
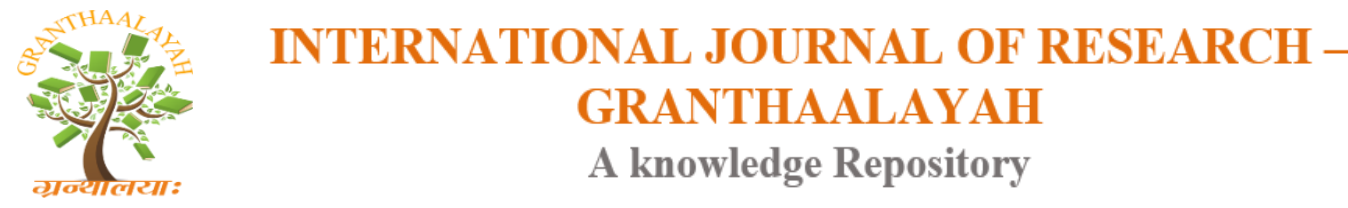

Science

\title{
ANALYSIS OF PROPERTIES OF CONCRETE USING MANUFACTURE SAND AS FINE AGGRIGATES
}

\author{
Vishal Gadgihalli ${ }^{* 1}$, Ramya M S ${ }^{2}$, Babitha Rani H ${ }^{2}$, Raghavendra Prasad Havanje \\ Dinakar $^{3}$, Lohith ${ }^{1}$ \\ ${ }^{*}$ UG Student, Department of civil engineering, Jain University, Bangalore, India \\ ${ }^{2}$ Assistant Professor, Department of civil engineering, Jain University, Bangalore, India \\ ${ }^{3}$ Research Assistant, Department of civil engineering, Jain University, Bangalore, India
}

\begin{abstract}
Aggregate in concrete acts as structural filler, these place a crucial than simple statement implies it is the material that the cement paste coats and blind together. Now a day's using river sand is prohibited by government, as these cause soil erosion. In this paper analysis of properties of concrete using manufacture sand as course aggregate is studied and verified the strength of concrete and temperature emitted due to chemical reaction to the normal Portland cement. Using manufacture sand as course aggregate the temperature emitted due to exothermal reaction of concrete has reduced. Although the compressive strength of the concrete has reduced compared to normal concrete where no admixtures were used to enhance the properties of concrete.
\end{abstract}

Keywords: Manufactured Sand; Temperature Retarders; Compressive Strength; Flexural Strength and Grade of Concrete.

Cite This Article: Vishal Gadgihalli, Ramya M S, Babitha Rani H, Raghavendra Prasad Havanje Dinakar, and Lohith. (2017). "ANALYSIS OF PROPERTIES OF CONCRETE USING MANUFACTURE SAND AS FINE AGGRIGATES." International Journal of Research Granthaalayah, 5(11), 338-342. https://doi.org/10.29121/granthaalayah.v5.i11.2017.2361.

\section{Introduction}

Manufacture sand also called $M$ sand this substitute of river sand for construction. This $M$ sand is manufactured by crushed sand is of cubic shape with grounded edges, washed and graded to as a construction material. The average of size of manufactured sand is less than $4.35 \mathrm{~mm}$. As sand mining from river is the direct cause of erosion and also impacts the local wild life [1]. Sand mining is regulated by law in many places, but is still glen done illegally [2]. Many countries like Australia, India, New Zealand, SiellaLeone, United states etc. have strictly regulating the mining of sand from river and coastal areas. Sand mining is a practice that is becoming an environmental issue in India. Environmentalists have raised public awareness of illegal sand mining in many states of India [3] [4]. Although $M$ sand aggregates are angular and rougher texture. These increase the demand of water. Water demand can be compensated with cement content. By 
adding water retarding admixtures $\mathrm{M}$ sand contains zecosilt, no oversized material and no marine products. Though $\mathrm{M}$ sand uses artificial fine aggregates to form, it causes less damage to environment as compared to rivers sand. This $\mathrm{M}$ sand is recommended for RCC purpose and brick/block works. $\mathrm{M}$ sand contains elements like $\mathrm{Si}, \mathrm{Al}, \mathrm{CA}, \mathrm{Mg}, \mathrm{Na}, \mathrm{K}, \mathrm{Fe}$ etc. Hence $\mathrm{M}$ sand is best substitute for river sand and coastal sand.

Manufacture sand used as a fine aggregate the absorbing temperature properties have reduced. But, increased in flexural strength, very less number of literature found related to present study, the author just compared his work with general concrete using river sand as fine aggregate.

\section{Methodology}

Fine Aggregates of $\mathrm{M}$ sand is collected; these aggregates are separated by all dust such as leaves and dust.

These fine aggregates are allowed to pass through 10mm sieve, and then aggregates which were passed were allowed to pass through $4.75 \mathrm{~mm}$ sieve. These aggregates are carefully handled because no other particles must not enter these aggregates are mixed with course aggregates and cement to form concrete powder using proportions, as per IS10262-2009

The specific gravity of safety matches was found 2.03 by Le-Chatelier principle [5] [6]. The compression and flexure strength were tested for 1, 7, 14, 21, 28 days after casting.

An empty spaced cube with bottom, size of $10 * 10 * 10 \mathrm{~cm}$ casted a walls of thickness $1 \mathrm{~cm}$ using concrete of manufacture sand as fine aggregates walls of thickness $1 \mathrm{~cm}$. Water of 1000c was filled in empty cube and the time consumed for reduction of temperature of water to 400c were noted down. This gives the time consumed by cube to reduce inner temperature of 1000c of water to 400c.

An empty cube casted by using manufacture sand as fine aggregates concrete size $10 * 10 * 10$ was inserted into another larger empty cube casted using plane cement concrete size of $15 * 15 * 10 \mathrm{~cm} .3 \mathrm{~cm}$ sufficient space was left between two cubes was filled with Water of 100c and top side of cube was closed by lid. Water temperature was noted down after $8 \mathrm{mins}$ for 1, 7, 14, 21, 28 days of similar casted samples. The difference between the water temperature noted after $8 \mathrm{~min}$ and the temperature at room temperature gives the amount of heat transmitted through the walls of inner cube. 


\section{Results and Discussions}

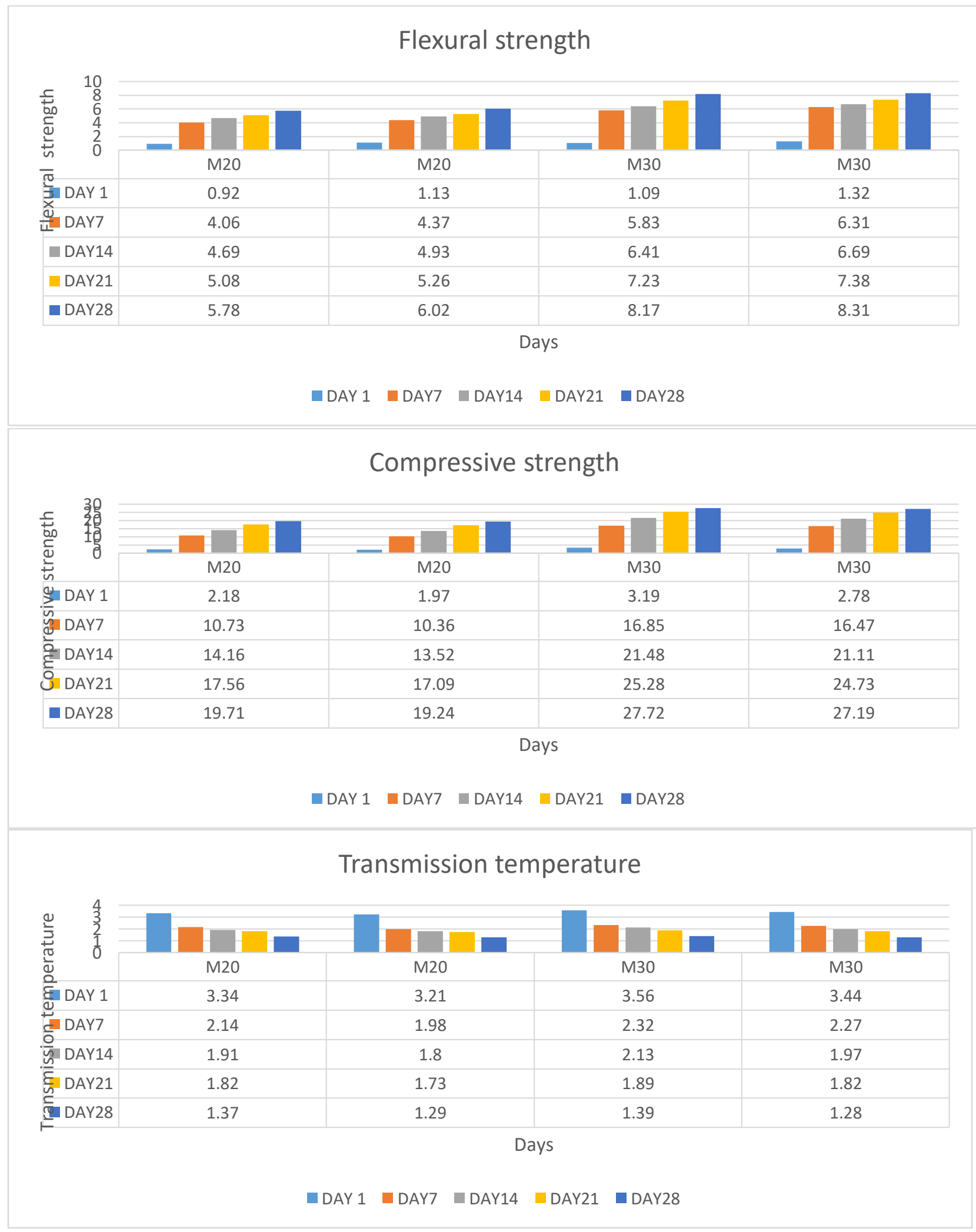




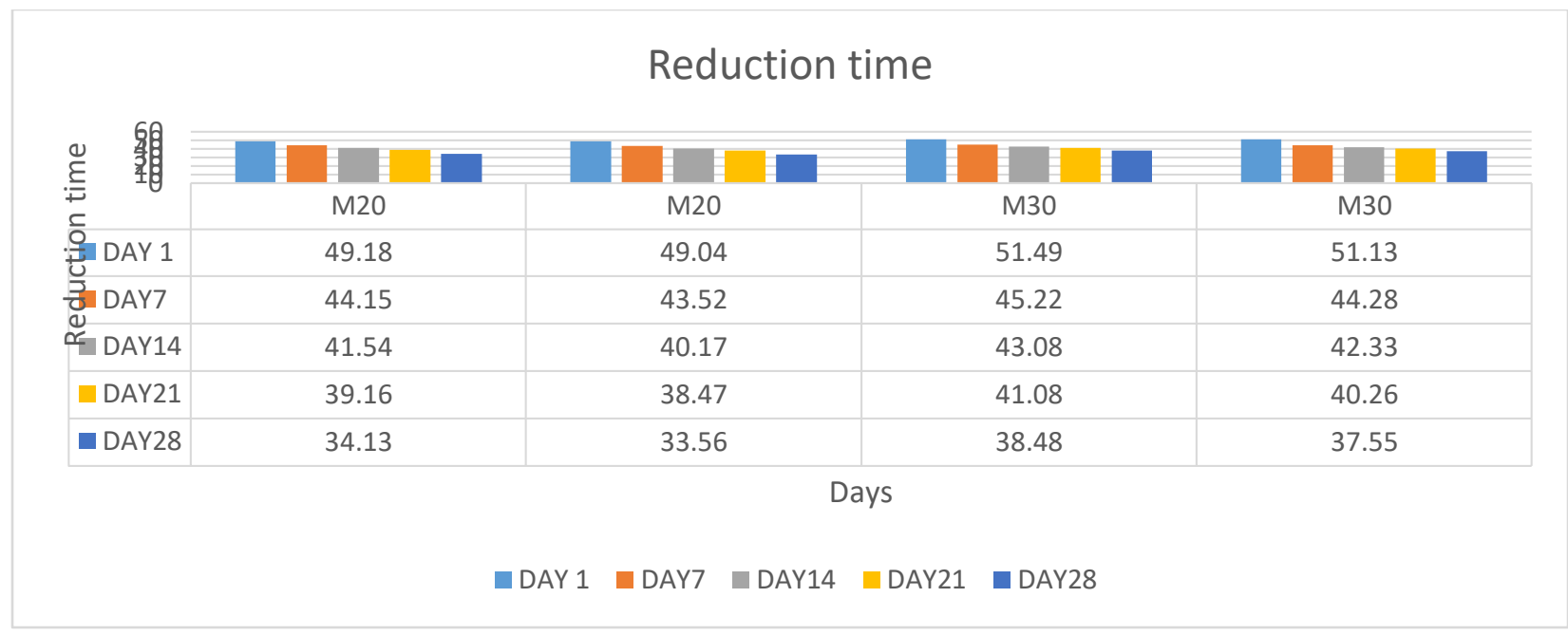

\section{Conclusions \& Recommendations}

From fig (1) it is observed that by using $M$ sand as fine aggregate the flexural strength of concrete has increased that is $6.02,8.31 \mathrm{M}$ pa by M20 and M30 grade for 28 days as compared to $5.78,8.17 \mathrm{M}$ pa of flexural strength obtained by using river sand as fine aggregate. The flexural strength has increased to $3.90 \%$ and $1.68 \%$ by M20 and M30 grade of concrete respectively.

Fig (3) represents that M20 of concrete with M sand transmitted less temperature that is 1.29 and $1.280 \mathrm{c}$ compared to normal concrete $1.370 \mathrm{c}$ and $1.390 \mathrm{c}$ respectively. About $5.83 \%$ and $7.91 \%$ of temperature reduced my M20 and M30 grade of concrete.

It is clear from fig (4) that the time taken by sample to cool down from $1000 \mathrm{c}$ to $400 \mathrm{c}$ was less while using $\mathrm{M}$ sand as fine aggregate that is $33 \mathrm{~min} 54 \mathrm{sec}$ and $37 \mathrm{~min} 55 \mathrm{sec}$ for M20 and M30 grade compared to ordinary concrete taking $34 \mathrm{~min} 13 \mathrm{sec}$ and $38 \mathrm{~min} 48 \mathrm{sec}$. Hence, it says the temperature liberated during chemical reaction may less in the $\mathrm{M}$ sand cubes.

Fig (2) shows there is no considerable change in compressive strength in all the grades.

\section{Acknowledgements}

Special thanks for Goutham Gadgihalli, HitheshNagothu, Megha.R for helping me in completing this work successfully. And I also thank my parents, teachers, friends and all elders who supported me.

\section{References}

[1] Rajadhyasha, Radha (10 jan2010). "No attacked brought to book so far". Times of India. Retrieved 22 April 2013.

[2] Biviju (24 March 2011). "Creeks and river up for sale". Times of India. Retrieved 22 April 2013.

[3] Singh Vijay (3 April 2012). "Ncp leader waves gun at tehsidar". Times of India. Retrieved 22 April 2003. 
[4] B, Viju( Oct 27 2009). "Sand mining issue haunts Naik “. Times of India. Retrieved 22 April 2013.

[5] Shanmugapriya T, Uma R.N: Optimum of partial replacement of M-sand by Natural Sand in high performance concrete with silica fume, 2, 2012, 75.

[6] Ramazan Demirboga, Rumstem Gul: The effect of expanded perlitre aggregate, Silica fume and fly ash on the thermal conductivity of lightweight concrete: 33(5), 2003, 723-727

*Corresponding author.

E-mail address: g.visha11912@ gmail.com 